Vol. 1, No. 2, 2020, pp. 37-41

DOI: https://doi.org/10.2921/07essr55700

Contents lists available at \ournal IICET

Education and Social Sciences Review

ISSN: 2720-8915 (Print) ISSN: 2720-8923 (Electronic)

Journal homepage: https://jurnal.iicet.org/index.php/essr

\title{
Development of arduino controlled robotic arm
}

\author{
Norfarida binti Awang ${ }^{1}$ \\ ${ }^{1}$ Politeknik Sultan Mizan Zainal Abidin, Malaysia
}

\begin{tabular}{l} 
Article Info \\
\hline Article history: \\
Received Apr $10^{\text {th }}, 2020$ \\
Revised May $20^{\text {th }}, 2020$ \\
Accepted Jun $27^{\text {th }}, 2020$
\end{tabular}

\section{Keyword:}

Robotic arm

Arduino

1Sheeld

\begin{abstract}
Robots are playing a vital role in today's industrial automation and monitoring system. As technology developed, these robots have increased their applications. Working robots that cooperate to the people makes the work less effort and uncomplicated. A robotic arm is a type of mechanical arm, usually programmable, with similar functions to a human arm. In this project, a programmable robotic arm is redesigned and implemented, and aimed to move using remote control and hand gesture from a certain distance by using wireless component. This robotic arm is based on android application control for remote operation. Inputs are sent to control the movement of the robot either to move in x-axis, y-axis or z-axis using 1Sheeld application on android smartphone. Five motors are interfaced to the microcontroller whereas one motor is used for gripper movement, while the other four motors are used at the joints of the robotic arm for movement. The android application device transmitter acts as a remote control by using hand gesture that has an advantage of adequate range, while receiver (1Sheeld) and Bluetooth device are fed to the microcontroller (Arduino) to drive DC motor via motor driver IC L298N for clockwise and anti-clockwise rotation. Remote operation is achieved by any smartphone with android upon Graphical User Interface (GUI) based touch screen operation.
\end{abstract}

C 2020 The Authors. Published by IICET

This is an open access article under the CC BY-NC-SA license

(https://creativecommons.org/licenses/by-nc-sa/4.0

\section{Corresponding Author:}

Norfarida binti Awang

Politeknik Sultan Mizan Zainal Abidin

Email: norfarida@psmza.edu.my

\section{Introduction}

Nowadays, the field of Robotics is very interesting and developing at a very fast rate aligned with the Industry 4.0 (iR4.0). Many types of wireless robots are being developed and are put to varied applications and uses. This innovation project tried to keep on in that direction and controlled a robotic arm wirelessly through an android mobile connected to an Arduino Uno that reads the analog data of the 1Sheeld and controls the motors and using a simple mechanism of the robotic arm to move. 1Sheeld is configured shield for Arduino and acts as an interpreter of the signal received from Arduino to the Android Smartphone(Khamil, Rahman, \& Gambilok, 2006).

This robotic arm has 4 joints and the maximum degree of rotation is 300 degrees. If the angle of each joint exceeds from its maximum angle, it will severely damage the wire of the motor, the gears and the body of the joints. The range of the remote controller is 100 meter and the voltage range are between 5 volts and 25 volts. It also can grab and pickup objects. The robot moves in up, down, left or right directions and picks up objects from one place and keeps at another desired place as directed by the movements of fingers and hand (S. Verma, 2013). The gripper of this robotic arm can lift and withstand load of $100 \mathrm{~g}$, if more than $100 \mathrm{~g}$ the joint became exhausted and unable to lift the load. 
Robotic arm is described by its degrees of freedom (DOF). This number typically refers to the number of single-axis rotational joints in the arm, where higher number indicates an increased flexibility in positioning a tool. This robotic arm has three DOF which is similar to the movement of human arm. The greater number of DOF the more complex the robotic arm.

Some of the existing robotic arm is complicated in moving an object from a far distance because it is not a wireless robotic arm. On 2012, studied found that Bluetooth is also a platform to control robot without using the cable. The movements of the robot are controlled remotely using Bluetooth connectivity(Yusoff, Samin, \& Ibrahim, 2012). The same result had been found in earlier study (Bray \& Sturman, 2001).Most of the robotic arm are heavy that makes them difficult to bring along anywhere. Thus, this robotic arm is a light and portable robotic arm that can be controlled wirelessly. This innovation also uses 1Sheeld as a remote to follow the hand gesture. It is operated \& controlled wirelessly with the help of hand gestures rather than controlling it manually through a conventional remote controller. This robotic arm has been developed successfully as the movement of the robot can be controlled precisely.

\section{Method}

Controlling of robotic arm is done by Arduino through DC motor connected to robotic arm. When user moves hand in any left, right, forward and backward then robotic arm is move according to direction of user hand.

This robotic arm is programmed with Arduino to control the movement of each joint. Arduino is compatible with both beginners and advance level people also, thus Arduino has been preferred over other controller(Khan, Imtiaz, Arain, SOOMRO, \& KHAN, 2019). It is simple to get use for the persons who are beginners and are using it and it is flexible for advance level users. The Arduino will define the axes and the directions of the movement of the robotic arm. The coding for all axes is well programmed in Arduino. Figure 1 shows the programming code for the $\mathrm{z}$-axis movement. If orientation sensor reaches certain point, the z-axis joint will move according to the input from the sensor. Basically, there are two values; positive value and negative value. When the orientation sensor gets positive value the DC motor will rotate clockwise direction while for the negative value the DC motor will rotate in anti-clockwise direction. The declared minimum value for $z$-axis joint is $25^{\circ}$ for positive value and $-45^{\circ}$ for negative value. Whenever, the input reach that value it will turn on the z-axis DC motor.

The programming in the Arduino will be shield using 1Sheeld. 1Sheeld is a new easily configured shield for Arduino as shown in Figure 2. It is a hardware shield that communicate over Bluetooth to android application, to transfer data between it and smartphone. It is connected to a mobile application that allow the usage of all android smartphones 'capabilities into Arduino programming.

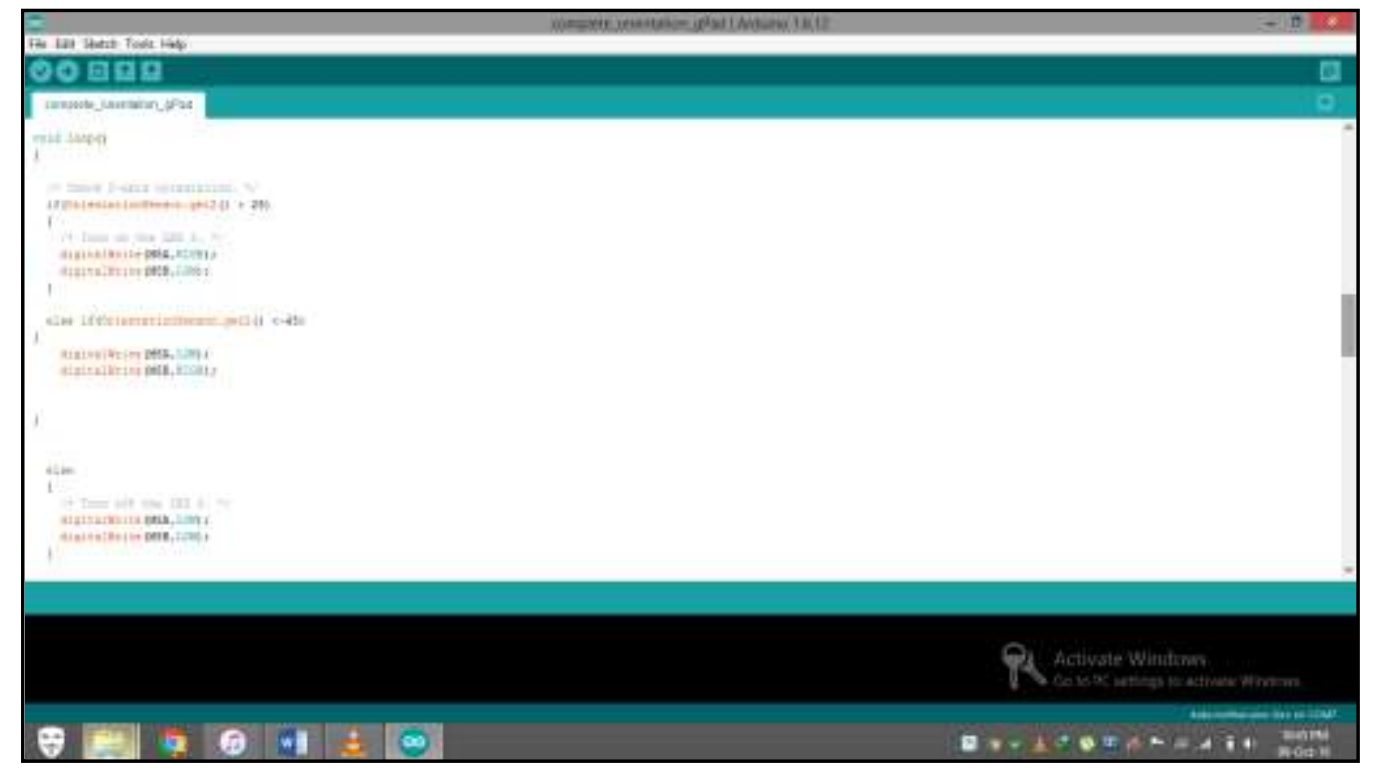

Figure 1. Programming code for $z$-axis 
1Sheeld can physically connected to Arduino board and acts as a wireless middleman, piping data between Arduino and android smartphone via Bluetooth. It also can manage the communication between 1Sheeld and smartphone. Thus, instead of buying the actual shield, 1Sheeld can be used to control the movement of the robotic arm such as left, right, up, down, rotate the gripper or grip object using phone's gyroscope. 5 volts is needed for operating 1 Sheeld and synchronizing with Arduino (G. Verma, Singh, Chugh, Kamti, \& Verma, 2016).

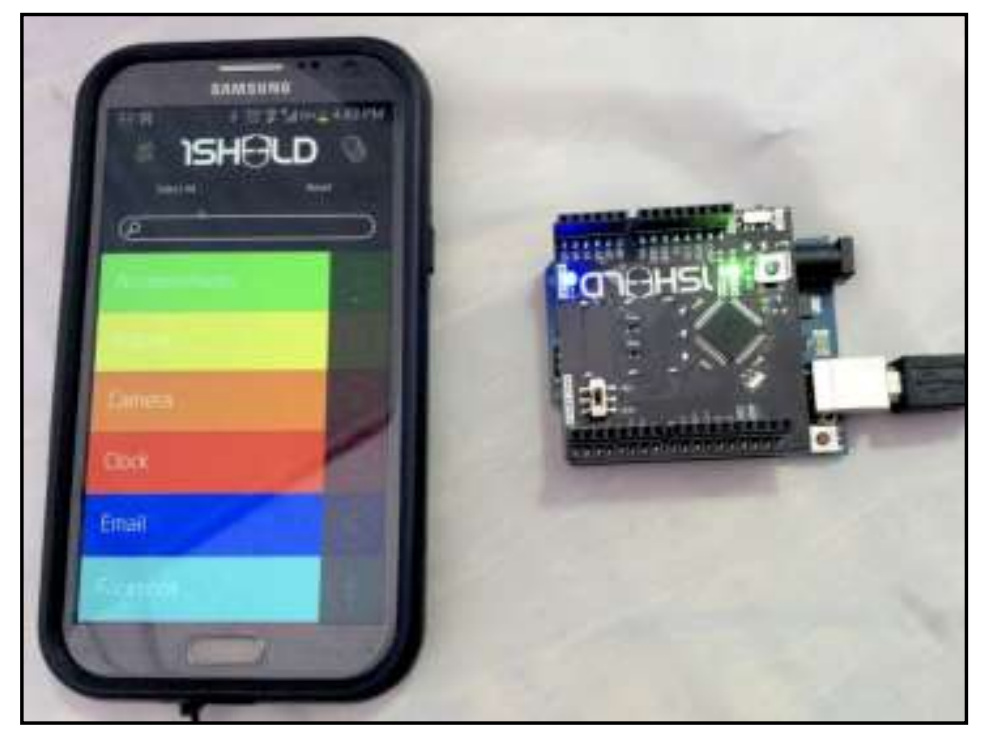

Figure 2. 1Sheeld as a shield for Arduino

\section{Results and Discussions}

\section{Bluetooth Connectivity}

In order to control the robotic arm, distance will influence the Bluetooth connectivity. Some experiments are carried out with different distance to see the connectivity of the Bluetooth. The experiments show that the Bluetooth has connectivity for the maximum of 100 meter range. More than 100 meter distance, the Bluetooth connectivity is failed, as shown in Table 1. Bluetooth connection using a smartphone is shown in Figure 3.

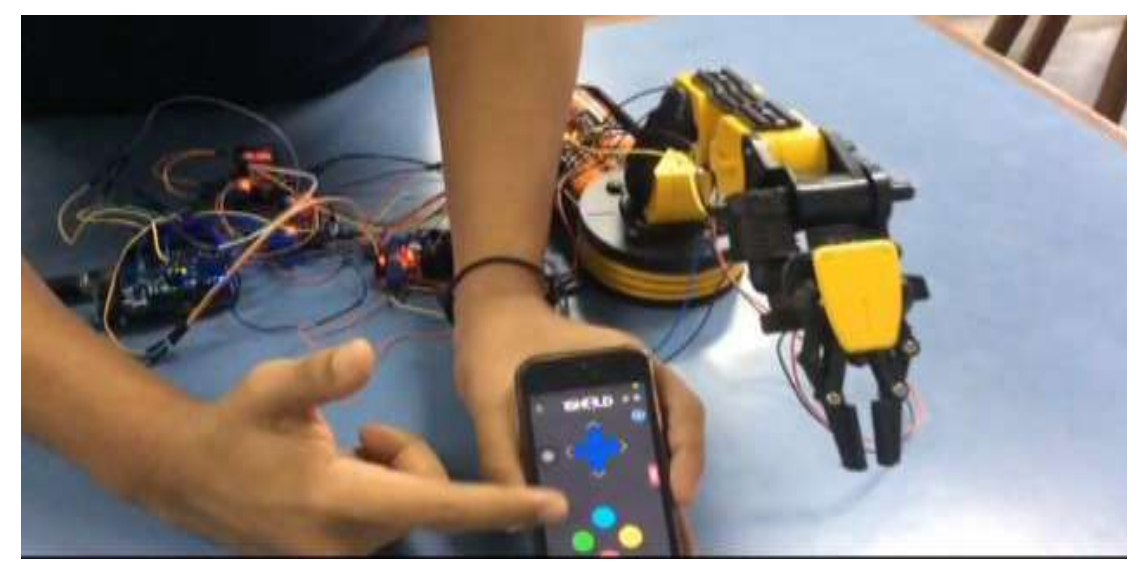

Figure 3. Bluetooth connection using a smartphone 
Table 1. Distance of bluetooth connectivity reached

\begin{tabular}{cc}
\hline Distance $[\mathrm{m}]$ & Connectivity \\
\hline 25 & has signal \\
\hline 50 & has signal \\
\hline 75 & has signal \\
\hline 100 & has signal \\
\hline 125 & no signal \\
\hline
\end{tabular}

\section{Angle of the joints}

Table 2 shows the maximum degree of the robotic arm joints can rotate. Each joint rotates in different angle and axis. Joint 1 rotates $0^{\circ}$ to $270^{\circ}$ from left to right motion or vice versa in y-axis, joint 2 rotates $0^{\circ}$ to $180^{\circ}$ from front to back motion or vice versa in x-axis, joint 3 rotates $0^{\circ}$ to $300^{\circ}$ from up to down motion or vice versa in $\mathrm{z} 1$-axis, and joint 4 rotates $0^{\circ}$ to $120^{\circ}$ from up to down motion or vice versa in $\mathrm{z} 2$-axis. If the angle of each joints exceeds from its maximum angle, it will severely damage the wire of the motor, the gears and the body of the joints. It can be shown in Figure 4.

Table 2. Angle of the joints

\begin{tabular}{cc}
\hline Joint & Degree $\left[{ }^{\mathbf{0}}\right]$ \\
\hline $\mathbf{1}$ & $0-270$ \\
$\mathbf{2}$ & $0-180$ \\
\hline $\mathbf{3}$ & $0-300$ \\
\hline $\mathbf{4}$ & $0-120$ \\
\hline
\end{tabular}
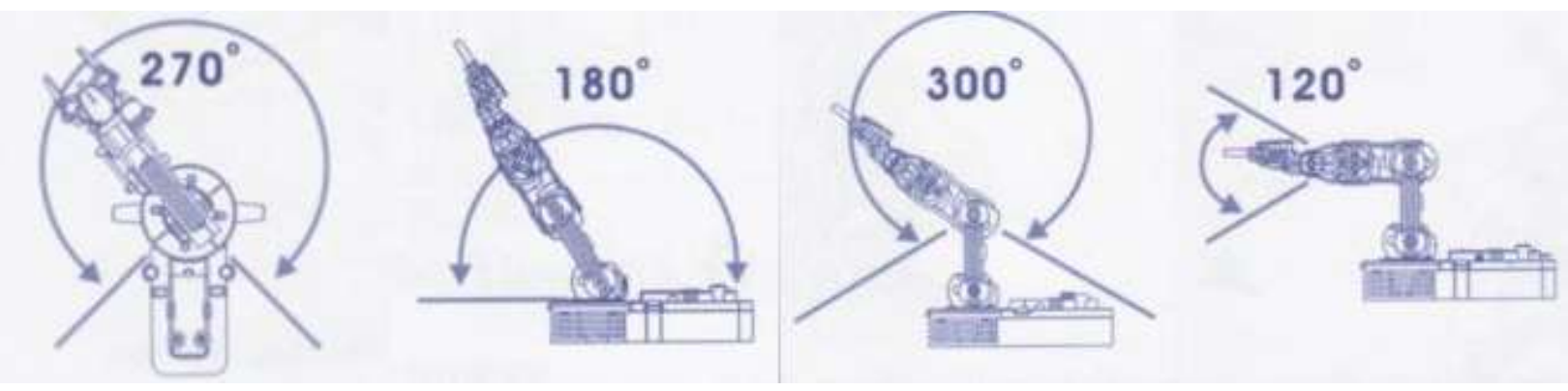

Figure 4. Four joints of the robotic arm

Load can be lifted by the gripper

Gripper mechanism is connected at the end of the robotic arm for the purpose of picking and placing an object. The gripper has its own maximum capacity of load to grip. Three objects with different mass were used as load in this experiment, as shown in Table 3. The gripper can lift and withstand load of $50 \mathrm{~g}$ and $100 \mathrm{~g}$. If more than $100 \mathrm{~g}$ the joint became exhausted and unable to lift the load. The experiment is shown in Figure 5.

Table 3 Load can be lifted by the gripper

Load [gram]

\begin{tabular}{cc}
\hline $\mathbf{5 0}$ & $\sqrt{ }$ \\
\hline $\mathbf{1 0 0}$ & $\sqrt{ }$ \\
\hline $\mathbf{1 2 0}$ & $\mathrm{X}$
\end{tabular}




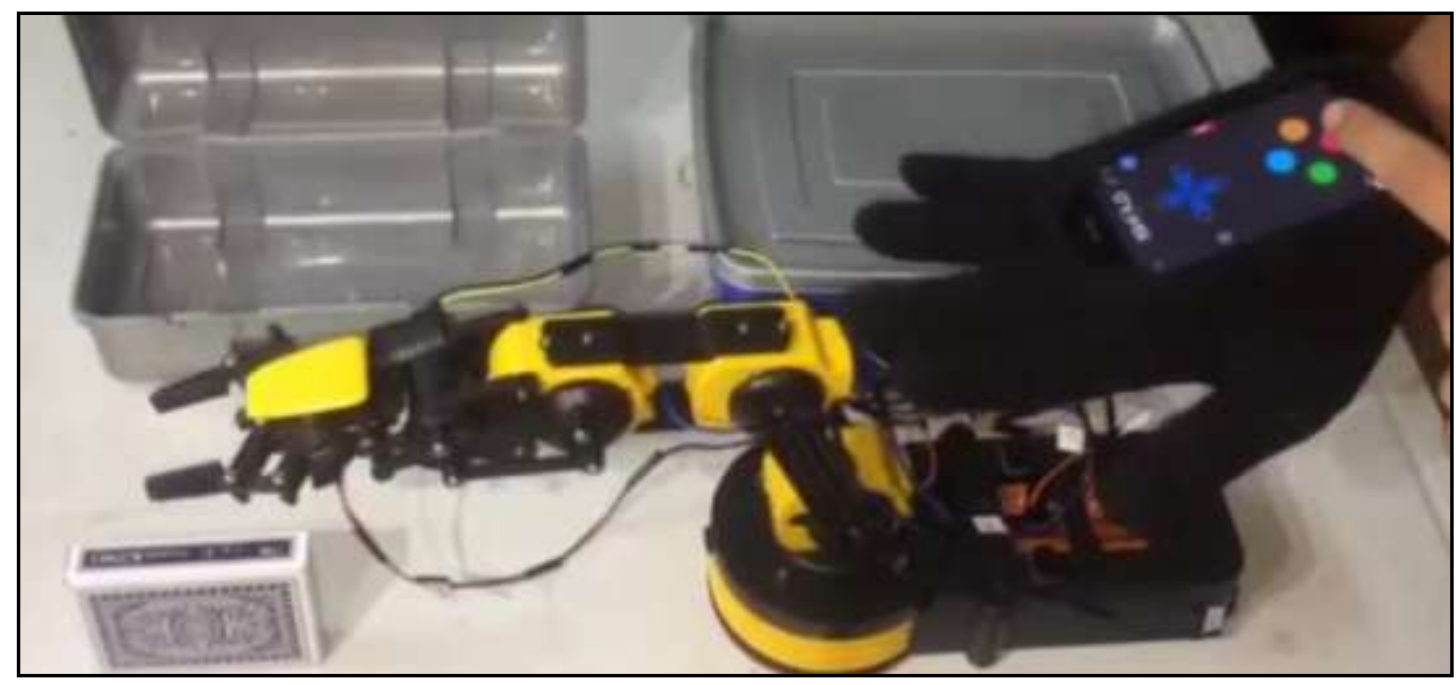

Figure 5. Gripper lift the load

\section{Conclusion}

This robotic arm has been developed successfully as the movement of the robotic arm can be controlled precisely. Its movement is easy to control and user friendly. It can move left, right, up, down and rotate according to the direction of the hand. This robotic arm control method is expected to overcome the problem such as placing or picking object in easy manner by using hand gesture. It also can be used in learning for subjects and classes that relate to robotics and programming. Outcome Based Education (OBE) concept can be applied in the classroom using this robotic arm. Students also can practice the concept of OBE in learning process. For future planning, it can be used for students in primary school as to facilitate the understanding of technical relationship of STEM (science, technology, engineering and mathematics). It also will introduce them to robotics and programming, so that they will actively engage in communication and collaborative skills. Thus, they will realize how great to discover the field of robotics.

\section{References}

Bray, J., \& Sturman, C. F. (2001). Bluetooth 1.1: connect without cables: pearson Education.

Khamil, K. N., Rahman, S., \& Gambilok, M. (2006). Babycare alert system for prevention of child left in a parked vehicle.

Khan, R. A., Imtiaz, R., Arain, A., SOOMRO, A. S., \& KHAN, D. (2019). Robotic Arm Controlled By Hand Gesture Using Leap Motion. University of Sindh Journal of Information and Communication Technology, 3(3), 145-148.

Verma, G., Singh, I., Chugh, S., Kamti, M., \& Verma, D. (2016). Automated red light enforcement camera for traffic control. Paper presented at the 2016 3rd International Conference on Computing for Sustainable Global Development (INDIACom).

Verma, S. (2013). Hand gestures remote controlled robotic arm. Advance in Electronic and Electric Engineering, $3(5), 601-606$.

Yusoff, M. A. K., Samin, R. E., \& Ibrahim, B. S. K. (2012). Wireless mobile robotic arm. Procedia Engineering, 41, 1072-1078. 